\title{
Causa diz-se em quatro sentidos: sobre a hermenêutica droyseana e a teoria da causalidade aristotélica*
}

\author{
The four meanings of "cause": on Droysen's Hermeneutics and Aristotle's \\ Theory of Causality
}

\author{
Renata Sammer \\ renatasammer@mac.com \\ Doutoranda \\ Pontifícia Universidade Católica do Rio de Janeiro \\ Rua Marquês de São Vicente, 225 - Gávea \\ 22453-900 - Rio de Janeiro - RJ \\ Brasil
}

\begin{abstract}
Resumo
Este artigo concentra-se sobre a teoria da interpretação de Johann G. Droysen a fim de elucidar alguns importantes aspectos de sua teoria da história (Historik). Procuraremos demonstrar como a teoria da causalidade aristotélica, além de estruturar a segunda grande parte da Historik, a Sistemática (Systematik) - onde encontramos "o modo histórico de existência", nas palavras de Hayden White -, pode ser relacionada às quatro etapas da teoria da interpretação droyseana. Assim, ilustraremos como a filosofia metafísica de Aristóteles fundamenta uma singular compreensão do pensamento histórico que, sem negar a sua qualidade representativa, abarca o notório presentismo droyseano. Por fim, indicaremos como esta filosofia afina-se à proposta formulada por Droysen ao longo da Historik de fundar a História na Ética.
\end{abstract}

\section{Palavras-chave}

Johann Gustav Droysen; Teoria da história; Ética.

\begin{abstract}
This article focuses on Johann G. Droysen's theory of interpretation in order to elucidate some important aspects of his theory of history (Historik). More specifically, it intends to show how the Aristotelian theory of causality structures the second half of the Historik, the Systematik - where we find the "historical mode of existence", as defined by Hayden White -, and how it connects to the four stages of Droysen's theory of interpretation. It will be shown how Aristotle's metaphysical philosophy inspires a singular understanding of historical thinking, which without denying it as a mode of representation also encompasses Droysen's openly professed presentism. Finally, it will be pointed out that this philosophy provides the main support for Droysen's idea that History should be founded upon Ethics.
\end{abstract}

Keywords

Johann Gustav Droysen; Theory of history; Ethics.

Recebido em: 15/2/2013

Aprovado em: 12/4/2013

* Esta pesquisa foi desenvolvida com o apoio financeiro da CAPES e do CNPq. 


\section{Introdução: A Historik, uma ética historicista}

Ao dar início às suas aulas de teoria da história, Droysen nota, sem deixar de demonstrar certa surpresa, que se os gregos deram origem a uma Ética, a uma Política e a uma Poética, é incompreensível que não tenham dado origem a uma teoria da história (Historik) (DROYSEN 1977, p. 45). Em seguida, Droysen nos oferece um breve histórico da disciplina buscando assim definir de maneira historicista - pela história da teoria da história - os seus contornos. Aristóteles teria lavrado o terreno sobre o qual seria construída a Historik, nos diz Droysen. Após algumas contribuições importantes - como, por exemplo, a crítica de Valla à doação de Constantino - Kant ergue as estruturas da disciplina que seria a partir de então edificada com certa constância: Herder, Schiller e Humboldt são os nomes citados por Droysen (DROYSEN 1977, p. 50). Contudo, nesta edificação segura, apenas no trabalho de Humboldt Droysen reconhece os contornos de uma disciplina que, apesar de sua caudalosa produção e significância política, encontrava-se em estado de grande confusão epistemológica (DROYSEN 1977, p. 53).

Embora seja possível traduzir o termo como "histórica" optamos com frequência pela expressão "teoria da história". Adotada por nomes como Gadamer, Koselleck e Rüsen, a Historik busca responder "o que significa pensar historicamente?". ${ }^{1}$ Se em Verdade e método (Wahrheit und Methode, 1960), Gadamer inclui Droysen entre os historicistas adeptos do método empático, em um artigo isolado, publicado "após a segunda guerra mundial", nota Hayden White, "Gadamer exaltou (hailed) Droysen como o fundador de uma hermenêutica distintivamente moderna, diferente daquela de Schleiermacher, Hegel e Dilthey, e como antecipador do pensamento de Martin Heidegger" (WHITE 1987, p. 84).2

A hermenêutica droyseana, entre o historicismo adepto do método empático e "uma hermenêutica distintivamente moderna", apresenta uma aparente contradição que, contudo guarda a sua especificidade. Tendo em vista essa especificidade, propomos analisar neste artigo a "Sistemática" (Systematik) - a segunda grande parte da Historik - na qual a teoria da interpretação histórica droyseana é apresentada. Se Droysen não limitou-se ao método empático, desenvolvendo ainda os pormenores de uma elaborada interpretação das idéias, ele jamais deixou de reconhecer a validez da representação histórica e a sua relação com a verdade.

\footnotetext{
1 "[A] tarefa dos estudos históricos consiste em que se aprenda a pensar historicamente". No original: "die Aufgabe der historischen Studien ist, dass man historisch denken gelernt hat" (DROYSEN 1977, p. 5). As demais traduções ao longo do artigo são, quando não indicadas, de nossa autoria. Para uma ampla discussão sobre a questão cf. CALDAS 2004

2 Como não deixa de notar Pedro Caldas: "a pretensão de dissolução do sujeito no objeto levaria, segundo Gadamer, o historista a cometer os mesmos equívocos do iluminismo. A crítica ao racionalismo feita pelos autores historistas não seria suficiente para encobrir o mesmo pressuposto de ambas as tendências de conceitualizar a história, a saber: desconsiderar a temporalidade como produtora de sentido, buscando a empatia ou a norma como ferramentas que superariam o fosso entre as épocas" (CALDAS 2006, p. 145). Buscando dar conta da especificidade do pensamento de Droysen, Caldas propôs ultrapassar os "limites do historismo" adotando o conceito de Bildung para a análise que faz da obra de Droysen (Cf. CALDAS 2006, p. 139). A proposta é interessante, pois a Bildung, por ser "inconclusiva e potencialmente ativa" (CALDAS 2006, p. 149), traduz com propriedade a dimensão formativa da hermenêutica droyseana e o presentismo de sua teoria. Como nota Caldas, Gadamer reduz a consciência histórica do século XIX ao historicismo adepto de método empático (Einfüh/ung) conduzindo assim Droysen à obscuridade. Obscuridade esta mantida e propagada por pesquisadores contemporâneos importantes como, por exemplo, Frank Ankersmit. Cf. ANKERSMIT 2005, p. 193-241. Sobre a inesperada aproximação de Droysen a Heidegger cf. GADAMER 1976, p. 48 apud WHITE 1987, p. 84.
} 
Aristóteles e Kant serão interlocutores privilegiados nesta análise: o primeiro por ter dado origem à teoria da história, como nos indica Droysen, além se ser um dos autores mais citados - senão o mais citado - por Droysen durante suas preleções, e o segundo por ser aquele que deu o impulso necessário ao ressurgimento da Historik após séculos de inação. Veremos como a filosofia metafísica de Aristóteles será associada à revolução kantiana - uma revolução copernicana às avessas - a partir da qual os objetos passam a girar ao redor do sujeito. Isto é, se Droysen manterá em sua teoria da história estrutura semelhante à kantiana, ele fará uso da teoria da causalidade aristotélica a fim de estabelecer os fundamentos e por conseguinte os limites da representação histórica. Mas não avancemos a letra do artigo. Como desafio à leitura da Historik podemos já indicar a maneira aparentemente contraditória pela qual o declarado presentismo de Droysen - em última instância, um relativismo - não deixa de reconhecer uma constante capaz de exercer a coesão necessária ao pensamento histórico. Assim compreendemos a célebre proposta droyseana de fundar a Historik na ética. ${ }^{3}$ Essa notória sugestão - "a ética seria a verdadeira filosofia da história" - , encontrada ao início da Historik, rejeita toda a tradição que por concentrar-se sobre a abstração filosófica ou sobre o puro empirismo deixa de compreender a relação entre o geral e o particular, entre o mundo natural e o mundo espiritual como verdadeiro desafio posto à reflexão histórica.

A teoria da história droyseana pode ser ainda identificada na maneira como o autor adjetiva a natureza humana: "sensório-espiritual" (geistig-sinnliche Natur). Desta maneira, Droysen busca superar o debate tão fortemente vivenciado em sua época entre os discípulos de Hegel - Heinrich Leo em particular - e a Escola Crítica rankeana, apontando para uma dualidade intrínseca ao homem que o coloca em contato direto e simultâneo com a experiência sensível e o pensamento abstrato. A filosofia da história ética droyseana é dotada de um aspecto trágico que pode ser sentido tanto na definição de natureza humana que propõe sensório-espiritual - quanto na maneira como evitará a resolução do conflito que identifica entre as sabedorias prática e filosófica. Afinal, a manutenção do conflito não apenas caracteriza, mas motiva a representação histórica. Na manutenção do pensamento trágico em sua ética indissociavelmente relacionada à dupla natureza humana reside toda a beleza da Historik.

Ao reconhecer Kant como o moderno iniciador de sua Historik, Droysen contudo rejeita o dogmatismo de sua moral. É por isso que devemos distinguir na tradução da Historik a moral kantiana da Sittlichkeit (eticidade) à qual Droysen se refere ao descrever as esferas de atuação humana (sittliche Kreise). De fato, há uma distinção fundamental a ser feita entre a ética antiga e a moral moderna,

\footnotetext{
3 Pedro Caldas, em um artigo recente dedicado à hermenêutica droyseana, reconheceu nas quatro formas de interpretação identificadas por Droysen pretensões de sentido distintas - empírico, lógico, empático e ideal. Como Caldas nota na introdução deste mesmo artigo, a hermenêutica droyseana nos coloca o desafio de relacioná-la à ética. Em última instância nos caberia investigar como hermenêutica e Bildung se relacionam (CALDAS 2011, p. 1). Desenvolvemos aqui o argumento de $A$. Assis que sublinha a manutenção de uma dimensão prática da história na teoria droyseana, embora Droysen não mais opere com a concepção exemplar da história (Cf. ASSIS 2009 , p. 22). Vale notar já de início que as quatro modalidades de interpretação identificadas por Droysen podem perfeitamente coexistir sem que estabeleçam entre si uma relação de hierarquia, embora Droysen não deixe de reconhecer o caráter criativo e portanto a distinção da interpretação das idéias.
} 
distinção esta à qual Droysen era sensível: a ética em sua versão droyseana não é dogmática, antes mantém a maleabilidade de sua homônima antiga. ${ }^{4}$ Se é possível identificar à luz da Terceira crítica certa flexibilidade na filosofia crítica kantiana, reconhecer que o enlace entre o sensível e o suprassensível não determina a experiência, tampouco seus fins, ${ }^{5}$ esse não parece ter sido o caminho escolhido por Droysen que permanece crítico à rigidez determinante da moral kantiana.

Como reflexo deste conflito irresolúvel entre o geral e o particular, entre a natureza espiritual e a natureza sensória, Droysen identifica dois sujeitos que tornam a representação histórica possível: um Eu empírico, temporalmente limitado, o ser-Eu (Ichsein) ao qual Droysen atribui a experiência sensível, e um Eu geral e abstrato capaz de dotar a experiência individual de universalidade, o Eu da humanidade (Ich der Menschheit). A relação entre os dois de mútua projeção e referência tem como fim comum, nos diz Droysen, o lógos, que em termos droyseanos pode ser compreendido como certa racionalidade intrínseca à história.

Mas há uma ressalva a ser feita: o sujeito droyseano que interpreta é também inconstante, um produto da história, e, portanto o conceito de fim (Zweckbegriff) que elabora, que rende universal, é também variável. Se a referência à representação histórica não pode ser encontrada nas leis que regem o mundo natural, tampouco o sujeito, maleável e inconstante pode oferecer a referência necessária à coesão histórica. Como seria então possível o pensamento histórico? Onde estariam guardadas as suas referências? Se ao reconhecer a historicidade do sujeito Droysen dá origem ao problema da referência, ele não deixará de estabelecer uma coesão possível para o pensamento histórico. É neste sentido que devemos compreender a teoria da interpretação droyseana contemplada à luz da teoria da causalidade aristotélica: se o sujeito que interpreta é diverso no tempo, ele jamais deixará de lidar com as aporias da representação histórica.

\section{A teoria da causalidade e a sistemática (Systematik) da verdade histórica}

Para os antigos gregos a particularidade do homem, o que o distinguia do mundo natural, era a sua mortalidade. É esta condição que possibilita alcançar a excelência por grandes feitos memoráveis. ${ }^{6} \mathrm{Na}$ época moderna, a história compreendida como processo, capaz de estender-se infinitamente em direções opostas, ao passado e ao futuro, de maneira a assumir a perenidade da natureza antiga é construída pelo contínuo trabalho da humanidade: "A humanidade" nos diz Droysen, "alcança o cosmos do mundo ético pelo trabalho dos indivíduos

\footnotetext{
4 "Com, efeito", diz Aristóteles em sua Ética a Nicômaco, "essa é a razão porque não são todas as coisas determinadas pela lei; pelo fato de haver alguns casos [e situações] em relação aos quais e impossível estabelecer uma lei, é necessária a existência de um decreto especial; pois aquilo que é ele próprio indefinido só pode ser medido por um padrão indefinido, como a régua plúmbea usada pelos construtores de Lesbos; tal como essa régua não é rígida, podendo ser flexibilizada ao formato da pedra, um decreto especial é feito para se ajustar às circunstâncias do caso" (Aristóteles, Ética a Nicômaco 1137b, 29-34).

5 Sobre a "flexibilidade" da filosofia crítica kantiana cf. "A faculdade de julgar, em geral, é a faculdade de pensar o particular como compreendido no universal. Se o universal (a regra, o princípio, a lei) é dado, então a faculdade de julgar que nele subsume o particular [...] é determinante. Se contudo, apenas o particular é dado e ela deve encontrar o universal, então a faculdade de julgar é apenas de reflexão" (KANT 1790, B XX VI). Tradução de Luiz Costa Lima apud COSTA LIMA 2000, p. 47.

6 Sobre a concepção grega do tempo Cf. ARENDT 1992. Assim escreve Hannah Arendt: "a humanidade descobre [na história] a imortalidade potencial da espécie humana" (ARENDT 1992, p. 109).
} 
que o formam e constroem" (DROYSEN 1977, p. 436).7 Ainda, "a nossa ciência", lembra, não é a história, "mas a istorie (a investigação) do que está posto neste cosmos" (DROYSEN 1977, p. 28). Há algo paradoxal na reflexão droyseana que identifica o mundo ético-histórico como um cosmos simultaneamente limitado e infinito. Se neste cosmos o novo pode surgir, as forças éticas (sittliche Mächte), substrato comum à espécie, funcionam como constantes capazes de elucidar as mais diversas formas da história. Em uma de suas passagens mais expressivas, Droysen diz, citando Aristóteles, que, enquanto os animais e as plantas podem ter seus semelhantes reunidos sob uma forma comum, capaz de definir assim o seu gênero, a característica capaz de reunir a humanidade sob um mesmo gênero é a história. O que faz da história o "conceito de gênero" (Gattungsbegriff) da humanidade (DROYSEN 1977, p. 16-17). Ter a história como "conceito de gênero" é sofrer a ação das "forças éticas" e reagir reproduzindo-as de maneira distinta. Assim, o cosmos que abarca o movimento incessante das "forças éticas" funciona como referência móvel, historicamente cambiante.

Se a humanidade é o agente que em seu trabalho dá forma e conserva este cosmos, o historiador é aquele que busca compreender as suas causas. Na abertura da Metafísica, Aristóteles reconhece "que há mais saber e conhecimento na arte do que na experiência, e consideramos os homens de arte mais sábios que os empíricos" (Aristóteles, Metafísica I, 1.7). A razão apresentada para tal distinção é de fato simples: "Com efeito", continua Aristóteles, "os empíricos sabem o 'quê', mas não o 'porquê'; ao passo que os outros sabem o 'porquê' e a causa" (Aristóteles, Metafísica I, 1.7). As causas (aition) são respostas às perguntas iniciadas por um "por que", i.e. às indagações sobre como o mundo e seus fenômenos (phainomena) vem-a-ser.

Aristóteles continua com um histórico da teoria da causalidade notando uma falha nesta tradição: a redução da teoria da causalidade à teoria dos princípios. Isto é, a teoria dos princípios reduziria a complexa relação entre as quatro grandes causas à primeira causa material. "Ora", diz Aristóteles, "causa diz-se em quatro sentidos". Sob as quatro aitia - material, formal, eficiente e final -, Aristóteles busca organizar todas as maneiras de dizer o porquê. ${ }^{8}$ "Aristóteles

\footnotetext{
7 Droysen identifica no "cosmos do mundo ético" (der Kosmos der sittlichen Welt) o objeto do historiador. Seria este mundo ético-histórico um universo fechado, onde, apesar de sua historicidade, é possível identificar certa constância, uma referência imutável - fundada na natureza política, sensório-espiritual, do homem dotado de lógos - para a filosofia política exposta na Historik? Devemos notar que o reconhecimento do mundo ético-histórico como um cosmos é incompatível com a interpretação que faz O. G. Oexle do historismo de Droysen. Reconhecendo nesse movimento a coexistência de ciências cujo objeto constitui um cosmos, e de ciências como pesquisa que, iniciadas sobretudo com a "revolução kantiana" que inverte a relação do conhecimento - "da razão aos objetos e não mais dos objetos à razão" -, Oexle vê no positivismo, no materialismo e no idealismo histórico ciências fechadas em um cosmos, pois lidam com um objeto finito. Já Droysen e Weber, por exemplo, teriam seguido a tradição kantiana e reconhecido que a ciência como pesquisa jamais alcança sua conclusão reinventando sans cesse seus próprios objetos (OEXLE 2001, p. 9). Buscaremos ressaltar o kantismo moderado de Droysen indicando na apropriação que faz da teoria da causalidade aristotélica uma possível definição do campo do historiador, i.e., a referência que estará à base do próprio pensamento histórico.

8 to dia ti Cf. VLASTOS 1969 , p. 294. G. Vlastos nota ainda que aition (em inglês "cause") deveria ser traduzido como "because", pois respondem as perguntas iniciadas por um "por que". Manteremos a tradução já proposta de aition como "causas" uma vez que Droysen segue esta direção (Ursache). Inserindo-se na tradição platônica de investigação do mundo natural tais questões podem ser assim exemplificadas: "por que passam as coisas a existir? Por que deixam de existir? Por que existem?" (Platão, Phaedo 96a, 6-10). Mas Platão teria atentado apenas para as causas material e formal, segundo Aristóteles (Metafísica I, VI, 7). Cf. VLASTOS 1969, p. 293.
} 
reconhece quatro princípios (arkhaí) ou categorias", nota Droysen, "pelas quais tudo que através de causas (Ursachen) é (e não através de si, como o que é divino) deve ser considerado" (DROYSEN 1977, p. 30).

Apenas o primeiro "porquê" - a primeira causa - é causa e princípio (Aristóteles, Metafísica I, 3.1-2). O exame da tradição que o precede, nota o estagirita, permitirá tanto "descobrir uma outra espécie de causas", ou dar "mais crédito às que acabamos de enumerar" (Aristóteles, Metafísica I, 3.1-2). Assim Aristóteles dedica ao menos dois livros às teorias de Tales, Empédocles e Anaxágoras de Clagômenes. A descrição não é exaustiva, pois visa distinguir a metafísica aristotélica de sua tradição pela substituição da discussão a propósito dos princípios por uma teoria da causalidade:

Com efeito, ainda que toda a geração e toda a corrupção procedam de um único princípio, ou de vários, por que é que isso acontece e qual a causa? Não é seguramente o sujeito o autor das suas próprias mudanças: por exemplo, nem a madeira, nem o bronze são a causa das próprias modificações, pois não é a madeira que faz a cama, ou o bronze a estátua, mas alguma outra coisa é a causa da mudança (Aristóteles Metafísica I, 3.9).

Ser, segundo a Metafísica aristotélica, não é apenas o que existe em ato, mas é também o que pode vir-a-ser, a potência. A doutrina do ato-potência aristotélica é vinculada na Metafísica a uma teoria da causalidade segundo a qual "causa" é tudo o que contribui para a realidade de um ser. Inserida na tradição platônica, a metafísica aristotélica pode ainda ser compreendida como uma crítica à Sofística. Mas se Aristóteles não abrirá mão do questionamento sobre o ser ou sobre a substância (ousía), ele reconhecerá a insuficiência da teoria platônica diante das múltiplas facetas de seu objeto. Droysen lembra o exemplo fornecido pelo próprio Aristóteles da feitura da estátua de um deus para o templo. Se na alma do artista está a imagem - Michelangelo dizia bastar retirar dos blocos de mármore tudo o que não era imagem - ele precisa da matéria na qual essa imagem será gravada. A qualidade desta matéria - bronze, mármore, madeira - por sua vez condicionará a imagem presente no artista: "sua concepção será diferenciada conforme se leve a cabo no bronze, no mármore, na madeira" (DROYSEN 1977, p. 29). Pensamento e matéria encontram-se aqui unidos, nota Droysen, dando origem a uma síntese que será refletida na qualidade da obra. "Mas o artista (aquele que move)", continua Droysen, "não gravaria na pedra a forma que vive em seu pensamento se a finalidade não o impulsionar para a ação: os objetos históricos seriam como o espelho do acaso e do arbitrário se neles não se reconhecessem as determinações de fim, que os move" (DROYSEN 1977, p. 30).

Ao contrário da interpretação tradicional inclinada a "platonizar" Aristóteles, que vê a Metafísica como o tratado onde os primeiros princípios alcançam a sua plenitude, buscaremos atentar para a sua fecundidade nela identificando além de uma teoria dos princípios, uma original teoria da causalidade. Isto é, os princípios cravados na ordem natural não mais limitam as causas do ser tampouco satisfazem as perguntas que suscita. Assim compreendemos também a interpretação droyseana da teoria da causalidade aristotélica: se o 
conhecimento empírico-indutivo é parte da construção de sentido histórico, a ontologia não se deixa dominar pela epistemologia.

Assim como Aristóteles repudia a tradição anterior que busca na rigidez dos princípios a origem de tudo o que é, Droysen notará que no conhecimento histórico, para além de seus materiais, há interpretação e há finalidade - ser é ato e potência. ${ }^{9}$ Se a ideia de fim contida nos sujeitos-intérpretes ou eficientes não é parte da realidade fenomênica e, portanto, não pode contribuir para o seu conhecimento objetivo, Droysen proporá, a partir da teoria da causalidade aristotélica, uma teoria da interpretação histórica onde a realidade não-fenomênica será incluída, onde coexistirão métodos tão diversos quanto o empírico, o dedutivo, o empático e a interpretação das ideias.

Hayden White notou sobre a teoria bipartida de Droysen que, se na sua primeira grande parte, na Methodik, encontramos o "modo histórico de pensar" (historical mode of thinking), na Systematik encontramos o "modo histórico de existência" (historical mode of existence) (WHITE 1992, p. 90). Droysen nos apresenta a Systematik como o "cosmos do historicamente investigável", como a tentativa de sistematização de um conhecimento reconhecidamente fluido e inconstante. O "homem politico dotado de lógos" aristotélico surge logo ao início desta segunda grande parte. Se o homem é um animal político, está em sua natureza viver politicamente (ton physei i pólis estí), a sua finalidade é o exercício desta natureza (physis télos estí) (DROYSEN 1977, p. 288). A afirmação aristotélica que encontra-se à base de sua Política ("o homem é um animal político dotado de lógos") e de sua Ética ("a finalidade do homem é o lógos") fundamentará também a Systematik de Droysen. É esta definição de homem que permitirá identificar a emergência das "comunidades naturais", "práticas" e "ideais" e suas respectivas "esferas éticas": o "mundo ético-histórico".

São quatro as formas a partir das quais podemos observar historicamente o mundo ético, nos diz Droysen: "(1) de acordo com a matéria (Stoff), na qual ele se forma (2) de acordo com as formas (Formen), nas quais ele se constitui; (3) de acordo com os trabalhadores (Arbeiter), através dos quais ele se constrói; e (4) de acordo com os fins (Zwecke) que, através de seu movimento, se concretizam" (DROYSEN 1977, p. 435-43). ${ }^{10}$

\footnotetext{
${ }_{9}$ Dada a importância da reflexão aristotélica para a teoria da história de Droysen, cito a passagem em sua integridade: "causa significa (1) aquilo do que, enquanto material imanente, algo vem a ser, e.g. o bronze é a causa da estátua e a prata a causa da travessa, [...]. (2) A forma ou a configuração, i.e. a definição da essência, [...] (3) aquilo do qual a mudança ou a manutenção se inicia; e.g. o conselheiro é a causa da ação, e o pai a causa da criança, e, em geral aquele que faz a causa do que foi feito e aquele que induz a mudança. (4) 0 fim, i.e., aquilo pelo qual algo é; e.g. saúde é a causa da caminhada, Para a pergunta "porque alguém caminha?" respondemos, "para que tenha saúde"; e assim falando pensamos ter dado a causa. A mesma coisa é verdadeira para todos os meios que intervenham antes de um fim, quando alguma outra coisa colocou o processo em movimento, [...]" (Metafísica V, 2). Uma versão semelhante pode ser encontrada na Física (II, 3).

${ }_{10}$ As edições da Historik divergem quanto à subdivisão da Systematik. Na edição mais abreviada de 1983 a Systematik é dividida segundo as quatro causas aristotélicas: "o mundo ético (sittlich) dever ser observado historicamente: (1) de acordo com a matéria, na qual ele forma; (2) de acordo com as formas, nas quais ele se constitui, (3) de acordo com os trabalhadores, através dos quais ele se constrói, (4) de acordo com os fins que, através de seu movimento, se concretizam". Esta divisão está também presente no Compêndio de 1882 sob o qual nos concentraremos. Já na mais recente edição de Leyh, 1977 (reconstituição do manuscrito de 1857), as três comunidades - naturais, práticas e ideais - dividem a primeira parte da Systematik - "As forças éticas (sittliche Mächte)" - sendo a segunda e última parte - "o homem e a humanidade". As comunidades naturais, práticas e ideais que representam os estágios da dialética que se estabelece entre indivíduo e mundo ético-histórico, entre necessidade e liberdade, e dão à história seu movimento surgem na edição de 1936 como partes de "(2) [o mundo ético] de acordo com as formas, nas quais ele se constitui". Seguiremos aqui o compêndio de 1882 .
} 
A apropriação que faz Droysen das quatro causas aristotélicas - material, formal, eficiente e final - teria levado White a reconhecer em sua teoria da história um embourgeoisement da Ética e da Política aristotélicas (WHITE 1992, p. 97). Ao introduzir a Systematik - "uma visão ordenada sobre o campo do historiador" Droysen nota que oferecer um resumo da história universal tal qual compreendida até então trairia a proposta da Historik. De fato, como poderia delimitar o campo do historiador pela apresentação de uma história já constituída se acabara de notar e mesmo de explicitar, na parte dedicada à metodologia, que o conhecimento histórico não possui limites definíveis e imutáveis? Mas a Systematik vai além da simples confirmação de suas teses anteriores: "Podemos dizer que esta segunda parte contém o sistema coordenado da verdade histórica, i.e. ela deve nos dar a Systematik, pela qual a verdade histórica se mostra (auseinanderlegen)" (DROYSEN 1977, p. 285). A partir da teoria da causalidade aristotélica é possível dizer que a "sistemática da verdade história" busca conhecer as causas do mundo ético-histórico. Mas a teoria da causalidade aristotélica-droyseana é de uma metafísica singular que reconhece tanto a parcialidade - não apenas inevitável, mas desejável - do sujeito quanto a objetividade do conhecimento histórico. Certamente a objetividade droyseana distingue-se da objetividade rankeana que o mesmo Droysen caracterizou como eunuca. Se a objetividade é possível, ela incorpora a interpretação do sujeito evitando tombar em campo infértil ou perder-se em abstrações a-históricas. De maneira semelhante, a metafísica aristotélica criticou o reducionismo materialista de seus antecessores sem contudo adotar acriticamente a teoria platônica das formas. Vejamos como a teoria da interpretação droyseana trata esta aparente contradição.

\section{Teoria da causalidade e teoria da interpretação}

A primeira grande parte da Historik, a Methodik, é dividida em quatro partes, a (1) Heurística (Heuristik), (2) a Crítica (Kritik), (3) a Interpretação (Interpretation) e a (4) Exposição (Darstellung). Droysen nos indica que a segunda grande parte da Historik, a Systematik, divide-se também em quatro partes que resultam "diretamente" (unmittelbar) das quatro partes apresentadas na Methodik (DROYSEN 1977, p. 60). Se a Systematik pode ser dividida (nos compêndios de 1857-1858 e 1882) segundo (1) "seus materiais", (2) "suas formas", (3) "seus agentes" e (4) "seus fins", é possível traçar um paralelo entre as duas grandes partes da Historik relacionando-as às quatro causas aristotélicas:

\begin{tabular}{|c|c|c|}
\hline $\begin{array}{c}\text { As 4 causas } \\
\text { aristotélicas }\end{array}$ & Methodik & Systematik \\
\hline Material & Heurística & $\begin{array}{c}\text { A história segundo seus } \\
\text { materiais }\end{array}$ \\
\hline Formal & Crítica & $\ldots$ suas formas \\
\hline Eficiente & Interpretação & $\ldots$ seus agentes \\
\hline Final & Exposição & $\ldots$ seus fins \\
\hline
\end{tabular}


Note-se que o "modo histórico de pensar" (Methodik) e o "modo histórico de ser" (Systematik), para não deixar de lembrar os termos de White, passam a ser à luz da teoria da causalidade aristotélica indissociáveis. Logo, se a heurística lida com os materiais provenientes do passado [fontes (Quellen), restos (Überreste) e monumentos (Denkmale)] aos quais dirigimos a "questão histórica" (historische Frage), a crítica Ihes dará a sua forma, i.e., dirá quem veio antes e quem veio depois, distinguirá o falso do verdadeiro. A interpretação colocará em jogo o sujeito - aquele que interpreta - expondo assim o seu ser historicamente devido e a exposição lidará com a finalidade da reflexão histórica, questionará a possibilidade de manutenção ou de reformulação das formas presentes do mundo ético-histórico que "sendo não [são] como deveria[m] ser" (DROYSEN 1977, p. 328). A crítica é uma técnica - semelhante à técnica que põe em prática o escultor - necessária para que conduzamos o material à forma imaginada (à interpretação). Logo a pergunta histórica surge do confronto entre os materiais da história e o sujeito eficiente. Nesse está a forma - ou a imagem - e a técnica para que determinado fim seja alcançado.

Droysen reservará à interpretação posição privilegiada em sua teoria da história lembrando que: "O caráter da investigação histórica é compreender investigando, é a interpretação" (DROYSEN 1977, p. 22). ${ }^{11}$ Droysen reserva ainda à interpretação - e não à crítica - a indagação sobre os começos. Ao introduzir o seu capítulo sobre interpretação, lembra que, embora possamos descamar nosso objeto como uma cebola (wie bei einem Zwiebel) é duvidoso que identifiquemos desta maneira a sua origem. Droysen descarta a discussão ao redor dos começos possíveis por considerá-la infrutífera, uma entediante contenda ao redor do ovo e da galinha. A adoção de "começos relativos" (relative Anfänge) deve servir a concepção historiográfica que os estabelece: "cada consideração histórica compreende apenas trechos de um encadeamento sem fim" (DROYSEN 1977, p. 161). Começos não encerram a história, tampouco princípios são capazes de satisfazer as questões sobre o ser. Lembremos aqui o pouco apreço que Droysen tinha pela Escola Crítica que, a seu ver, limitava-se cegamente ao exame das fontes. "A prática da Escola Crítica", nota, "é incomparavelmente melhor que a sua teoria" (DROYSEN 1977, p. 146).

Droysen reconhece quatro tipos de interpretação histórica: 1) A interpretação pragmática (pragmatische Interpretation), 2) a interpretação das condições (Interpretation der Bedingungen), 3) a interpretação psicológica (psychologische Interpretation), e, 4) a Interpretação das idéias (Interpretation der Ideen). "Fechar o círculo da compreensão" é considerar as quatro etapas acima como etapas complementares, mesmo sucessivas, deste processo (DROYSEN 1977, p. 166). Embora Droysen não o faça explicitamente, é possível considerar também estas quatro etapas à luz da teoria da causalidade aristotélica.

Sabemos que a primeira causa aristotélica é a causa material. A interpretação pragmática droyseana lida diretamente com "a simples existência do material histórico tal como se encontra ordenado pela crítica" (DROYSEN 1983, p. 185). A

\footnotetext{
${ }_{11}$ No original: "das Wesen der geschichtlichen Methode ist forschend zu verstehen, ist die Interpretation".
} 
esta ordem pré-estabelecida, a interpretação pragmática oferece um complemento ordenando as fontes por analogia ou por comparação. Como não deixa de notar Caldas, a intepretação pragmática é capaz de estabelecer um conhecimento objetivo a partir de um método empírico-indutivo, algo que Droysen não deixa de reconhecer como parte constitutiva do conhecimento histórico (CALDAS 2011, p. 3). A interpretação das condições droyseana busca a forma, as condições de determinados "presentes passados" (vergangene Gegenwarten) que circundam as fontes, os restos e os monumentos. Deduzir circunstâncias a partir desses vestígios é conhecer a sua forma, seu locus, poderíamos ainda dizer, em um determinado tempo e em um determinado espaço. A terceira causa aristotélica, a causa eficiente, expõe as forças que iniciam o movimento que dão forma ao material. Ao identificar um indivíduo "condutor" buscaremos compreender seu modo de agir fazendo uso da interpretação psicológica. A interpretação psicológica, contudo, possui seus limites: é válida apenas enquanto capaz de mostrar como certo indivíduo ilumina as esferas éticas de seu tempo contradizendo-as ou confirmando-as. O valor deste indivíduo para nós, lembra Droysen, não se deve à sua personalidade, mas ao seu significado histórico adquirido. ${ }^{12}$

O "círculo da compreensão", nota Droysen, fecha-se apenas com a interpretação das idéias que, por estar voltada às "grandes potências éticas" que nos movem, a nossas "idéias", aproxima-se da quarta causa aristotélica, a causa final. Assim é possível ultrapassar a nossa presença "individual e efêmera" (individuelles und ephemeres Dasein), participando de maneira ativa da "configuração das grandes potências éticas". Logo a interpretação das idéias pode ser também identificada como "interpretação das potências éticas" (DROYSEN 1983, p. 187). Através destas "potências" ou "idéias", temos a oportunidade de liberar-nos de nosso "pequeno eu", indica Droysen, e participar ativamente das comunidades éticas. Nesta última etapa da interpretação o sujeito é criador, com sua interpretação traz algo novo ao mundo.

Se há dúvidas quanto a possibilidade de associar as quatro formas de interpretação catalogadas por Droysen às quatro causas aristotélicas, vale lembrar um exemplo, elaborado pelo próprio Droysen, a fim de explicar a seus alunos como complementam-se as etapas da interpretação. Para que possamos caminhar, diz Droysen, é necessário que tenhamos: 1) os membros associados uns aos outros segundo um mecanismo específico, 2) a correta reação de nossos músculos aos desníveis do solo ou às suas lacunas, enfim, às suas condições, 3) vontade de nos mover (potência) e 4) a finalidade, a idéia de fim que nos leva a nos mover.

Se Kant nos mostrou como o objeto gira ao redor do sujeito - e não o sujeito ao redor do objeto -, subordinando assim o objeto ao sujeito, é importante que nos perguntemos se Droysen, ao recuperar a filosofia metafísica de Aristóteles

\footnotetext{
12 Cf. DROYSEN 1977, p. 205-08; CALDAS 2004, p. 131. Assim, para recuperar aqui o exemplo citato por Droysen, Georg von Podiebrad defendeu o direito de Estado face às pretensões da Igreja, conquistando ainda a independência nacional da Boêmia. Nele encontram-se, lembra Droysen, as idéias de Estado, Igreja e nação. Contudo, a compreensão de seu presente passado só podemos alcançar ao identificar o "ponto histórico" onde se encontra. Este "ponto" encontramos apenas ao cruzar a linha de seu presente com a linha das configurações posteriores de Estado, nação e Igreja. Este mundo presente, conhecido, o mundo ético (sittlich) em sua mais recente configuração, é o que nos auxiliará a formular a "pergunta histórica" (historische Frage) e assim encontrar o "ponto histórico" a partir do qual poderemos, através de nossa interpretação produzir novo sentido.
} 
após reconhecer-se moderadamente kantiano não busca uma referência ao conhecimento histórico exterior ao sujeito, mas também ao mundo natural, uma referência móvel e cambiante que abarque ambos. É sintomático neste sentido que Droysen insista no conhecimento da história pela história, ou de maneira mais geral, do lógos pelo lógos. Desta maneira, ao subsumir o sujeito à história, Droysen aloca o referente necessário à construção do pensamento histórico não mais neste sujeito incerto e variável, mas na própria história. Pensamento histórico e existência histórica se entrelaçam caracterizando assim a filosofia ética da história droyseana. Deste modo, o lógos cambiante funcionará como um fundo de semelhança identificável não apenas na ordem natural, mas na maneira como os homens concebem a própria natureza.

\section{Causa final e filosofia ética da história}

$\mathrm{Na}$ teoria da causalidade aristotélica, as causas formal, eficiente e final coincidem com frequência. Se entre as plantas e os animais, a finalidade é a perpetuação da forma, a finalidade de um tigre é vir-a-ser um tigre - "forma, agente e telos coincidem" (Física 198a25) -, a fonte natural de mudança, a causa eficiente, é "a forma da coisa, ou o que é, pois essa é sua finalidade" (Física 198b3). Se a forma do homem é a história - este é seu conceito de gênero (Gattungsbegriff) - , a sua finalidade, o que o move, é também a história. À luz da ética aristotélica poderíamos ainda dizer ser a característica comum aos homens, o lógos que os diferencia dos demais animais, também a sua finalidade. Aspirar ao lógos pelo lógos, este é, afinal, o tema da Ética a Nicômaco. São conhecidos os exemplos de Aristóteles: a finalidade de um flautista é tocar bem a flauta e a do sapateiro é fazer bons sapatos (Aristóteles, Ética a Nicômaco 1097b25). Deste modo a finalidade do homem - esse animal político dotado de lógos - é bem exercitar o lógos. A versão droyseana da teoria da causalidade aristotélica aproxima-se da Ética ao reconhecer no lógos a finalidade da história: "a finalidade da humanidade, o lógos, realiza-se construindo" (DROYSEN 1977, p. 389). Assim reconhecemos no lógos, além da finalidade, o material da história: O lógos, "que se quer cumprir e que se cumpre", termina por constituir a própria história, o "mundo ético em movimento" (DROYSEN 1977, p. 385).13

Deste modo, Droysen fecha o cosmos do mundo ético: nesta sucessão de fins alcançados apresenta-se a história, tem o historiador o seu material. Droysen estabelece assim uma relação de circularidade para a teoria da causalidade aristotélica, semelhante à circularidade das deliberações éticas onde fins alcançados tornam-se meios para novos fins. ${ }^{14}$ Caldas já identificou um

\footnotetext{
${ }^{13}$ Embora a aproximação do lógos droyseano ao lógos aristotélico seja possível - e sugerida pelo próprio Droysen -, vale lembrar as dificuldades que Dr. Fausto encontrara ao início do "Evangelho segundo João" - "No princípio era o Verbo". O lógos, na versão grega do evangelho, seria o Verbo, o Senso, a Potência ou a Ação? (GOETHE, Faust IV, 1). Como veremos mais adiante, na teoria da história de Droysen, Deus, o sujeito da história, limita, por estar oculto, o conhecimento do homem "por uma diferença ontológica" (CALDAS 2008, p. 115). Deste modo é possível reconhecer uma ética historicista de inspiração antiga na teoria da história droyseana.

$14 \mathrm{Um}$ exemplo de como a metodologia estabelecida por Droysen para a história pode funcionar como uma deliberação ética pode ser encontrado no comentário de Carlo Antoni sobre a obra de Droysen: "[...]; é por isso que ele reverte o julgamento tradicional sobre Demóstenes, sobre Felipe da Macedônia e sobre a civilização helênica - [...]. Demóstenes, diz ele, teria inutilmente patronado a defesa das liberdades atenienses, pois a poeira de pequenos estados gregos, com sua política fechada, não teria chance alguma de sair vitoriosa
} 
"fio solto" no pensamento droyseano: se "o presente é a dimensão privilegiada do conhecimento histórico", como interpretar as "frases referentes ao aspecto teológico, frequentemente encontráveis nas páginas de sua Historik?" (CALDAS 2008 , p. 114). Neste caso, como podemos associar a circularidade da interpretação droyseana, onde meios tornam-se fins, sem uma filosofia da finalidade que oriente estas isoladas deliberações? Para Caldas, "o sujeito da história (Deus) fica de tal forma oculto, que o conhecimento do homem [...] é sempre limitado por uma diferença ontológica" (CALDAS 2008, p. 115). Se a teoria da história droyseana não rompe com uma concepção teleológica da história, ao fundá-la na ética, Droysen permite que o indivíduo coloque-se ativamente sobre a história. Assim, a finalidade da história, embora não deixe de atuar de maneira oculta, será pontualmente definida pelos "trabalhadores da história" (DROYSEN 1977, p. 13). Como não retornar assim à centralidade do sujeito que há pouco havíamos questionado? Afinal ele guarda a finalidade, ainda que momentânea, da história.

Se no sistema kantiano a vontade livre encontra-se submetida à lei moral - o que terminaria por conceder ao indivíduo a sua autonomia - em Droysen a vontade livre retira do mundo público a sua motivação: "[do mundo ético] definimos nossos fins" (DROYSEN 1977, p. 34). Nos mantemos aqui próximos à arquitetura da Primeira Crítica e de seus juízos determinantes por ser esta a leitura que faz Droysen de Kant: "as abstrações, tanto as materialistas quanto as dogmáticas e as lógicas, são sempre formas de consideração" (Betrachtungsformen) (DROYSEN 1977, p. 34), escreve Droysen criticamente. E, desta maneira, é possível extrair uma constante: "está na natureza humana que esta se comporte eticamente, e isso foi assim em todos os tempos" (DROYSEN 1977 , p. 34). Sua referência portanto está na heteronomia do mundo público, na ética em seu sentido antigo, no reconhecimento de que "formas de consideração" serão infinitamente reformadas guardando contudo uma constante: o modo ético-histórico de ser humano.

A metodologia droyseana pode ser assim compreendida como uma peça deliberativa - da identificação do material à exposição - ao interior de sua teoria da história. Mas a finalidade de sua ética não é dogmaticamente forjada por um fim que Ihe é exterior. Seus fins são dotados de história, são a própria história, testemunham o enlace momentâneo entre a experiência sensível e o universal. Assim, a história faz-se objeto de si mesma. A circularidade da teoria da interpretação droyseana não apenas a aproxima de uma ética, mas desestabiliza as categorias de sujeito e objeto subsumindo o conhecimento

\footnotetext{
do grande duelo com o Oriente asiático. Pertenceria apenas à monarquia macedônica, monarquia militar, de conquistar a Ásia e de transformar a civilização grega, ainda estreitamente municipal, em uma civilização universal. Droysen fez da época alexandrina até então considerada como uma era de decadência e corrupção, a grande época, a época decisiva para a história do mundo, aquela que possibilitou o encontro e a fusão da civilização grega com a civilização asiática. A força, no caso, teria sido o instrumento indispensável da cultura. É assim que a Prússia de Potsdam oferecia seus serviços à Alemanha de Weimar, aquela dos poetas e dos filósofos. Em sua apologia à monarquia macedônica, Droysen não esquecera de louvar o corpo dos oficiais macedônicos, tão ricamente providos do sentido de honra, instrumento da cultura grega no Oriente; ele inaugurara assim esta aliança entre o corpo de professores e aquele dos oficiais, tão característica da Alemanha oficial até a primeira grande guerra" (ANTONI 1963, p. 80).
} 
histórico à própria história. Como nos diz Droysen, "também a finalidade, a idéia de humanidade, presente em cada alma, encontra-se em movimento" (DROYSEN 1977, p. 386).

Podemos ainda levantar a hipótese de que, como as formas de interpretação são complementares e ainda gradativas, também as formas expositivas se iniciam com a "mimesis da pesquisa" para culminar na "exposição discursiva" ou "deliberativa" (Erörterung). Esta seria a mais nobre dentre as formas expositivas e a finalidade do trabalho historiográfico. De fato, a exposição historiográfica voltada ao debate público conclui o projeto droyseano de fazer da historiografia uma ética. Seu intuito era reabilitar a historiografia segundo o espírito dos sofistas: muito mais "vida científica e movimento" (wissenschaftliches Leben und Bewegung) pode ser encontrado no "boca a boca" (Mund zu Mund) do que nos livros, diz (DROYSEN 1977, p. 258).

\section{Conclusão: coesão ética}

Como pensar a história sem subsumi-la à objetividade eunuca ou condicioná-la às múltiplas interpretações? Se podemos compreender a sistemática "pela qual a verdade histórica se mostra", sob a forma de quatro indagações sobre o ser, é possível estabelecer assim uma coesão para a história que não seja historicista ou presentista?

Droysen reconhece que a finalidade da formação ética é uma formação inconclusa - i.e. a solução do conflito não é a sua resolução mas o seu reconhecimento - na qual as sabedorias prática e filosófica coexistem. O reconhecimento da limitação presente da compreensão humana (Dasein und Jetztsein) não impede que valores gerais possam ser evocados. "Estas ideias [éticas]", nota ainda Droysen, "não são o próprio Absoluto, mas são absolutos relativos, o Absoluto, como nós o conhecemos e apreendemos até aqui" (DROYSEN 1977, p. 39). "A verdade", continua, "não está no "desenvolvimento permanente de uma lei natural que se transforma ao conservar-se, mas [n] a dialética de algo em si contraditório, que se conserva ao se transformar sem descanso" (DROYSEN 1977, p. 295, grifo meu). Este seria o "verdadeiro dualismo" tal qual nos aponta Droysen. O dualismo próprio às ciências naturais e à filosofia, que busca estabelecer leis gerais é, quando aplicado à história, falso (falscher Dualismus) (DROYSEN 1977, p. 41). Esse "falso dualismo" é, diz ainda Droysen, aético (unsittlich), pois não considera a contribuição do indivíduo enquanto "totalidade relativa" ao movimento da história.

A rejeição do falso dualismo e o reconhecimento de um dualismo fundamental e insuperável capaz de pôr em movimento o mundo ético - conservá- lo ao transformá-lo - nos permite estabelecer um "encadeamento ético" para a história. E assim conclui Droysen sem deixar de citar Schiller: "apenas neste encadeamento ético está correto quando diz o poeta que a história do mundo é o tribunal do mundo" (DROYSEN 1977, p. 41). ${ }^{15}$ 
Ao interpretar a frase de Schiller tornada célebre por Hegel à luz do encadeamento ético, Droysen oferece um contraponto ao reconhecidamente inevitável - por Droysen mesmo recomendado - presentismo. Isto é, a contingência não pode ser erigida como verdade sem ser antes confrontada a uma perspectiva universal. Esta seria de fato condição necessária à permanência do pensamento histórico, do questionamento incessante que move a "dialética do contraditório" droyseana. O encadeamento ético ou a coesão ética funcionará assim como uma constante que, segundo a teoria da história de Droysen, está à base do pensamento histórico. "O resultado desta consideração é de natureza muito prática", nota Droysen,

Certamente, a manutenção do direito, a administração do Estado [...] têm lados completamente técnicos em si. Mas quem elas integra, busca compreendê-las pela sua profunda conexão, [vê que] não há nelas outra coisa senão sua coesão ética (ethischer Zusammenhang), sobre a qual quer projetar idéias vivas e em constante devir (lebende und werdende Ideen), e o caminho a esta compreensão é o método histórico que é para o mundo intelectual a ferramenta (Organon) assim como o método físico é para o matemático (DROYSEN 1977, p. 39).

Qualquer tentativa de reconhecer no presentismo droyseano ou em sua exigência pela parcialidade do historiador os antecedentes do decisionismo pós-historicista seria frustrada, pois em sua teoria da história, presentista e antropocêntrica, é mantida a possibilidade de um encadeamento ético. Assim, não apenas o Estado, o direito e as demais esferas éticas de atuação humana surgem como objeto para o historiador, mas também - e sobretudo - a coesão ética que as mantém, i.e. o seu fundamento humano que, apesar das variações das formas sob as quais se apresenta, permanece constante. Esta constante mutável, fruto da "dialética de algo em si contraditório, que se conserva ao se transformar sem descanso", servirá como referência comum ao pensamento histórico. Se a limitação da ética aristotélica é a ausência de uma reflexão sobre a história, Droysen, ao contrário colocará a história ao centro de sua ética estabelecendo assim uma possibilidade de coesão para as experiências do homem no tempo.

Ter a ética como filosofia da história, significa reconhecer um modelo de racionalidade próprio à história, inconcluso, em deslocamento constante, incapaz de limitar-se ao geral ou ao particular. A teoria da causalidade aristotélica por questionar o ser desdobrando-o em causas distintas - não sucessivas, contudo complementares - oferece um interessante pano de fundo à teoria da interpretação droyseana. Essa deve ser compreendida como atividade inconclusa não apenas por ser incapaz de abarcar seus objetos definitivamente, mas por ser sua função o autoexame e o autoquestionamento incessantes.

Se os antigos nunca deixaram de se questionar sobre a relação entre a excelência humana e a ordem natural - mesmo uma ética antropocêntrica como a aristotélica não se abstém desta indagação - , o rompimento moderno com esta tradição imporia gradualmente limitações ao pensamento histórico. Afinal, como é possível estabelecer critérios imutáveis de verdade capazes de abarcar a 
variedade de interpretações que multiplica-se à medida que adentram o mundo novos indivíduos? Droysen estabelece no cosmos do mundo ético-histórico uma constante inconstante que fundamentará o incessante questionamento sobre a história. O indivíduo não é descartado de sua teoria da interpretação, mas um oximoro o define como "totalidade relativa". Se Gadamer viu em Droysen indícios da filosofia heideggeriana, vale notar que, se era objetivo de Heidegger romper com a tradição metafísica ocidental, Droysen, ao contrário, busca recriá-la. De fato, a representação, embora não limitada a um princípio, objeto ou sujeito, permanece indispensável ao pensamento histórico. Droysen encontra na metafísica de Aristóteles a teoria necessária ao questionamento do que é naturalmente diverso e inconcluso. A referência para o pensamento histórico, a sua condição de existência, não se deixa encerrar sob forma alguma. Seja o mundo ético em movimento ou o ser do lógos no mundo, o objeto da história não se deixa controlar. É este o fundamento trágico desta disciplina que a aproxima da ética antiga: a variabilidade de seu objeto não impede o seu questionamento.

\section{Referências bibliográficas}

ANKERSMIT, F. Sublime Historical Experience. Stanford: University Press, 2005.

ANTONI, C. L'Historisme. Genebra: Librairie Droz, 1963.

ARENDT, H. Entre o passado e o futuro. São Paulo: Perspectiva: 1972 [1961].

ARISTÓTELES. Ética a Nicômaco. São Paulo: Edipro, 2009.

Metafísica. São Paulo: Abril Cultural, 1983.

ASSIS, A. Droysens Historik und die Krise der exemplarischen Geschichtstheorie. In: BLANKE, H.-W (org.). Historie und Historik: 200 Jahre Johann Gustav Droysen. Köln: Böhlau, 2009.

BARASH, J.A. Politiques de I'histoire: I'historicisme comme promesse et comme mythe. Paris: PUF, 2004.

CALDAS, P.S.P. Que significa pensar historicamente: uma interpretação da teoria da história de Johann Gustav Droysen. Tese de doutorado. PUC-RJ, CCS, Departamento de História, Programa de Pós-Graduação em História Social da Cultura, 2004.

- O limite do historismo: Johann Gustav Droysen e a importância do conceito de Bildung na consciência histórica alemã do século XIX. Revista Filosófica de Coimbra, n. 29, 2006, p. 139-160.

. 'A ética é a verdadeira filosofia da história': Bildung e Hermenêutica em Droysen. In: OLIVEIRA, C.; MOLLO, H.; BUARQUE, V. (orgs.). Caderno de resumos \& Anais do 5o. Seminário Nacional de História da Historiografia: biografia \& história intelectual. Ouro Preto: EdUFOP, 2011.

Uma dificuldade no caminho do historicismo: uma leitura de Droysen com filtro marxista. In: ARAUJO, V. L. de; VARELLA, F.; MOLLO, H. M.; 
MATA, S. R. da (orgs). A dinâmica do historicismo: revisitando a historiografia moderna. Belo Horizonte: Argumentum, 2008, p. 107-124. COSTA LIMA, L. Mímesis: desafio ao pensamento. Rio de Janeiro: Civilização Brasileira, 2000.

DROYSEN, J. G. Historik. Stuttgart/Bad Cannstatt: Frommann- Holzboog, 1977 [1857-1882].

Histórica, Lecciones sobre la Enciclopedia y metodologia de la historia. Barcelona: Editorial Alfa, 1983 [1857].

GADAMER, H. G. On the problem ofSelf-Understanding. In: Philosophical

Hermeneutics. Berkeley; Los Angeles; London: University of California Press, 1976 [1962], p. 44-58.

OEXLE, O. G. L'historisme en débat: de Nietzsche à Kantorowicz. Paris: Aubier, 2001 [1996].

VLASTOS, G. Reasons and causes in the Phaedo. The Philosophical Review. Durham: Duke University Press, vol. 78, n. 3, 1969, p. 291-325.

WHITE, $\mathrm{H}$. The content of the form: narrative, discourse and historical representation. Baltimore/London: The Johns Hopkins Press, 1992. 